Original Article

\title{
The Evaluation of The Relationship Between Antibody Response and COVID-19 Disease Severity
}

\author{
Yusuf Taha GULLU1 ${ }^{\text {(D) }}$, Nazmiye Tibel TUNA ${ }^{1}$ (D) , Tuba GULLU KOCA² \\ ${ }^{1}$ Department of Pulmonary Medicine, Ondokuz Mayıs University Faculty of Medicine, Samsun, Turkey \\ ${ }^{2}$ Internal Medicine Clinic, Bursa Ali Osman Sonmez Oncology Hospital, Bursa, Turkey
}

\begin{abstract}
Background World Health Organization (WHO) reported COVID-19 as a pandemic, on March $11^{\text {th }}$, 2020. The quick and accurate diagnosis is crucial to provide the appropriate treatment and isolation process. Immunity against COVID-19 is essential for disease control. There is scant information about antibody response and disease severity. In this study, we aimed to investigate the relationship between clinical severity and COVID antibody response.

Material and Methods Hospitalized PCR $(n=10)$ and/or radiologically $(n=31)$ proven 35 COVID-19 patients were included in the study. The blood samples were collected at least eight days after the onset of symptoms and studied by using the COVID-19 IgG/IgM Rapid Test. Patients were divided as mild $(n=14)$, severe $(n=12)$ and critical $(n=9)$ according to COVID-19 disease severity. The results were compared among the groups.

Results A total of 35 COVID-19 patients' (mean age: $54.65 \pm 16.51$ years, Male/Female: 23/12) rapid test results were compared according to clinical severity. A significant correlation was observed between disease severity and IgG results in both PCR positive $(p=0.007)$ and whole patients $(p=0.026)$. The positive IgG ratio was significantly low in the mild patient group while it was higher in severe and critical patients.

Conclusions Our study reveals that the greater antibody response occurs with the more serious COVID-19 disease. The application of the rapid test, in addition to PCR, may be used as a clue to foresee the clinical progression. These tests not only have an important role in diagnosis with PCR tests but also are associated with disease severity.
\end{abstract}

Turk J Int Med 2021;3(2):49-55 DOI: $\underline{10.46310 / \text { tjim. } 839313}$

Keywords: antibody; SARS-CoV-2; COVID-19; disease severity; immune response

Received:December 14,2020;Accepted:January 16,2021; Published Online:April 29, 2021

Address for Correspondence:

YusufTaha Gullu, MD

Department of Pulmonary Medicine, Ondokuz Mayıs University Faculty of Medicine,

Samsun, Turkey

E-mail:yusuftaha.gullu@omu.edu.tr 


\section{Introduction}

The outbreak of the Coronavirus disease 2019 (COVID-19) in Wuhan spread rapidly all over the world. World Health Organization (WHO) reported COVID-19 as a pandemic, on March $11^{\text {th }}, 2020 .{ }^{1}$ The virus was first observed in China, but European and American content countries are the most affected. From the first case, which was reported on March $11^{\text {th }}, 2020$, to July $8^{\text {th }}$, 2020, the total number of reported cases in Turkey was 207.897, with 5.260 deaths. ${ }^{2}$

Immunity against COVID-19 is crucial for disease control. There is scant information about antibody response and disease severity. COVID-19 can be diagnosed by using clinical, radiological, and laboratory tests. The most frequently encountered symptoms are fever, cough and fatigue. Progression to acute respiratory distress syndrome (ARDS), septic shock, bleeding, coagulation dysfunction might be observed in severe cases. ${ }^{3}$ These symptoms are not specific features of COVID-19 since they are similar to that of other viral diseases or pneumonia with other respiratory tract pathogens. The chest computed tomography (CT) of COVID-19 patients revealed the ground-glass opacities and bilateral patchy shadowing predominantly located peripherally. ${ }^{4}$ Currently, the only way for diagnosis of COVID-19 is polymerase chain reaction (PCR) based viral RNA detection from the nasopharyngeal and oropharyngeal swabs. These real-time Reverse Transcription Polymerase Chain Reaction (rRT-PCR) test requires certified laboratories, expensive equipments, trained technicians, and it has false-negative results for rRT-PCR of COVID-19. ${ }^{5}$ False-negative results may be due to the inadequate education of health professionals for sample collection, different stages of infection (in some radiologically typical patients for COVID-19, the RNA remains negative), quality of the test. ${ }^{6}$ Due to these disadvantages, radiologic and laboratory tests were also employed for COVID-19 diagnosis.

Publications on severe acuterespiratory syndrome (SARS) and the Middle East respiratory syndrome (MERS) revealed that specific antibodies were found in $80-100 \%$ of patients two weeks after the onset of symptoms. ${ }^{7,8}$ Antibody responses to SARS-CoV-2 are not fully understood, and the clinical benefits of serological tests are still uncertain., ${ }^{910}$ Serological tests have more advantages over PCR; such as easy access to the specimen, faster test results, minimal need for equipment, specialized laboratories and workload. However, we still have many obscures about the disease; the immune response plays a crucial role in the course of the disease. As we all know, immunoglobulin M (IgM) is the first antibody to be produced in response to infections before the generation of humoral IgG responses that are crucial for long term immunity. ${ }^{11}$ In this study, we aimed to investigate the relationship between clinical severity and COVID antibody response.

\section{Material and Methods}

This study was conducted on 35 hospitalized COVID-19 patients [PCR ( $\mathrm{n}=10)$ and/or radiologically $(n=31)$ proven] in the pandemic clinic of Ondokuz Mayis University, Faculty of Medicine. After the local ethics committee approval (approval date: April 10, 2020; approval number:2020/149) consent given patients were recruited to the study. Combined oropharyngeal and nasopharyngeal swab samples were taken from all participants upon admission, $48^{\text {th }}$ hours, and $96^{\text {th }}$ hours of hospitalization. SARS-CoV-2 (2019-nCoV) qPCR Detection Kit" (Bioeksen Bio-Speedy R\&D Co, Ltd, Turkey) was used to demonstrate the presence of SARS-CoV-2.

The blood samples that collected at least eight days after the onset of COVID symptoms were studied with COVID-19 IgG/IgM Rapid Test Cassette (Citus Diagnostic Inc. Ovios). The COVID-19 IgG/IgM Rapid Test Cassette was compared with confirmed clinical diagnosis. The study included 446 specimens for IgG and 456 specimens for IgM (Table 1 and Table 2). Clinical information including travel and exposure history, starting of clinical symptoms and radiological and laboratory findings (Lactate dehydrogenase, D-Dimer, Ferritin, Creatine phosphokinase, C-reactive protein, Troponin-I, Procalcitonin, and Lactate) were collected. Patients were divided as mild (non-pneumonia and mild symptoms, $\mathrm{n}=14$ ), severe (dyspnea, respiratory rate $\geq 30 / \mathrm{min}$, blood oxygen saturation $\leq 93 \%$, the partial pressure of arterial oxygen to fraction of inspired oxygen ratio $50 \%$ within 24 to 48 hours, $n=12$ ) and critical (respiratory failure, septic shock, or multiorgan dysfunction, $\mathrm{n}=9$ ) according to COVID-19 disease severity. ${ }^{12,13}$ The results were compared among these groups. 
Table 1. Validity of the COVID-19 IgG/IgM Rapid Test for IgG results

Method

COVID-19 IgG/IgM

Rapid Test Cassette

for IgG

Total Results
Confirmed Clinical Diagnosis

Total Results $\begin{array}{llll}\text { Positive } & 75 & 2 & 77\end{array}$

$\begin{array}{llll}\text { Negative } & 0 & 369 & 369\end{array}$

$\begin{array}{lll}75 & 371 & 446\end{array}$

Table 2. Validity of the COVID-19 IgG/IgM Rapid Test for IgM results

\section{Method}

COVID-19 IgG/IgM

Rapid Test Cassette

for IgM
Confirmed Clinical Diagnosis

Negative

Positive

Negative

Total Results

\section{Positive}

78

7

85
3

368

371
Total Results

81

375

456

\section{Statistical Analysis}

The research data were evaluated by using "SPSS (Statistical Package for Social Sciences) for Windows 21.0 (SPSS Inc, Chicago, IL)" licensed to Ondokuz May1s University. Definitive statistics were given as average \pm standard deviation, median (minimum-maximum), frequency distribution, and percentage. Chi-square, Fisher's precision test was used for qualitative evaluations.

\section{Results}

The demographics and results of 35 patients (age $=54.65 \pm 16.51, \quad$ Male $/$ Female $=23 / 12$ ) were collected. Most of these patients had co-morbid diseases including cardiovascular disease $(n=9)$, cancer $(n=6)$, hypertension $(n=3)$, chronic renal failure $(n=2)$, diabetes mellitus $(n=1)$, chronic obstructive pulmonary disease $(\mathrm{n}=1)$, and asthma $(n=1)$ while 12 patients had no comorbidity (Table 3). No significant difference was observed between having comorbidity and disease severity $(\mathrm{p}=0.236)$.

The most frequently encountered complaints during admission were fever (65.7\%), cough (57.1\%) and shortness of breath (SOB,57.1\%). Except SOB no significant difference was observed between the admission complaints and disease severity. SOB was observed 3 of 14 mild patients while it was observed 9 of 12 severe patients and 8 of 9 critical patients $(\mathrm{p}=0.002)$.

Radiological evaluation reveals bilateral ground glass appearance in 11 patients (31.4\%) at Chest X-ray and 19 patients (54.3\%) in Chest CT. Other chest CT findings including messy infiltration $(n=4)$, pleural effusion $(n=3)$, consolidation $(n=3)$ and unilateral ground glass appearance $(n=2)$ were also observed.

Ten patients have positive PCR test results on admission, while the remaining 25 patients had three consecutive negative PCR test results. Five of the triple-negative PCR patients' COVID-19 $\mathrm{IgG} / \mathrm{IgM}$ rapid test was resulted as positive for IgG. The remaining 20 patients with negative antibody test results were considered as a probable case since they had typical clinical symptoms and radiological findings. The evaluation of the COVID-19 IgG/IgM rapid test results revealed that eight patients (22.9\%) were positive for IgM, and ten patients were positive for IgG (28.5\%).

In the whole patient group and particularly PCR positive group, the IgM and IgG positivity rate were significantly higher in severe and critical patients compared to the mild group (Table 4). 
Table 3. Socio-demographic data of patients

\begin{tabular}{ll}
\hline Study Parameter & Value \\
\hline Age & $54.65 \pm 16.51$ \\
Gender, $\mathrm{n}(\%)$ & \\
$\quad$ Male & $23(65.7)$ \\
$\quad$ Female & $12(34.3)$ \\
Health personnel, $\mathrm{n}(\%)$ & $9(25.7)$ \\
Suspected contact history, $\mathrm{n}(\%)$ & $9(25.7)$ \\
Co-morbid diseases, n (\%) & \\
$\quad$ None & $12(34.2)$ \\
$\quad$ Cardiovascular disease & $9(25.7)$ \\
Cancer & $6(17.14)$ \\
Hypertension & $3(8.5)$ \\
Chronic renal failure & $2(5.7)$ \\
Diabetes mellitus & $1(2.8)$ \\
Chronic obstructive pulmonary disease & $1(2.8)$ \\
Asthma & $1(2.8)$ \\
Smoking History, n (\%) & \\
Never smoked & $20(57.1)$ \\
Ex-smoker & $12(34.3)$ \\
Active smoker & $2(5.7)$ \\
Passive smoker & $1(2.9)$ \\
\hline
\end{tabular}

Table 4. Comparison of groups in terms of IgG and IgM results in all patients and PCR positive patients

\section{Disease Severity}

$\begin{array}{cccc}\begin{array}{c}\text { Mild } \\ (\mathbf{n}=14)\end{array} & \begin{array}{c}\text { Severe } \\ (\mathbf{n}=12)\end{array} & \begin{array}{c}\text { Critical } \\ (\mathbf{n}=9)\end{array} & \mathbf{p} \\ 0 / 14 & 5 / 7 & 5 / 4 & 0.007 \\ 0 / 14 & 4 / 8 & 4 / 5 & 0.026\end{array}$

Immunoglobulin G

(Positive/Negative)

Immunoglobulin $\mathrm{M}$

(Positive/Negative)

PCR positive patients, $(n=10)$

$\begin{array}{lcccc} & \begin{array}{c}\text { Mild } \\ (\mathbf{n}=5)\end{array} & \begin{array}{c}\text { Severe } \\ (\mathbf{n}=\mathbf{2})\end{array} & \begin{array}{c}\text { Critical } \\ (\mathbf{n}=3)\end{array} & \mathbf{p} \\ \begin{array}{l}\text { Immunoglobulin G } \\ \text { (Positive/Negative) }\end{array} & 0 / 5 & 0 / 2 & 0 / 3 & 0.007 \\ \begin{array}{l}\text { Immunoglobulin M } \\ \text { (Positive/Negative) }\end{array} & 0 / 5 & 1 / 1 & 3 / 0 & 0.019\end{array}$


The evaluation of laboratory results reveals that SpO2, LDH, Ferritin, and CPK measurement on admission were significantly different among the groups (Table 5).

\section{Discussion}

Our study reveals that COVID IgM/IgG Rapidtest results were significantly correlated with disease severity. In our study we have mild, severe and critical disease group but we have no moderate disease group. Since patients with pneumonia had respiratory distress at the time of admission, we put them in severe disease group. Laboratory results, including acute phase reactants, were significantly higher in critical patients, while oxygen saturation was significantly higher in mild patients.

Table 5. The laboratory results of patients on admission
Severe acute respiratory syndrome coronavirus-2 (SARS-CoV-2) can initially be detected with PCR test 1 to 2 days prior to the onset of symptoms in the upper respiratory samples and can persist for 7 to 12 days in moderate cases and up to 2 weeks in severe cases. MolecularteststhatdetectviralRNA may have false-negative results due to sample types, sampling time, accurate sampling technique, sample quality, transport, and storage conditions. In a study of 205 patients with COVID-19, bronchoalveolar lavage fluid specimens demonstrated the highest positive PCR rates (93\%), followed by sputum (72\%), nasal swabs (63\%), bronchoscopy brush biopsy (46\%) and pharyngeal swabs (32\%) (14). Although PCR is the gold standard for confirming the infection, rapid antibody tests can be used, especially in severe and critical cases, as a diagnostic tool. Our results show that $28.5 \%$ of our COVID patients have a positive

\begin{tabular}{|c|c|c|c|c|}
\hline & Mild $(n=14)$ & Severe $(n=12)$ & Critical $(n=9)$ & $\mathbf{p}$ \\
\hline $\mathrm{SpO}_{2}(\%)$ & $96.79 \pm 1.76^{\mathrm{a}, \mathrm{b}}$ & $92.25 \pm 4.39^{\mathrm{a}}$ & $93.78 \pm 3.15^{b}$ & 0.004 \\
\hline White Blood Cells & $7.51 \pm 2.76$ & $8.37 \pm 5.44$ & $8.22 \pm 5.72$ & 0.879 \\
\hline Neutrophils & $5.04 \pm 2.46$ & $6.56 \pm 5.07$ & $5.73 \pm 5.34$ & 0.670 \\
\hline Lymphocyte & $1.73 \pm 0.83$ & $1.13 \pm 0.97$ & $1.67 \pm 0.85$ & 0.205 \\
\hline Lymphocyte (\%) & $28.4 \pm 18.21$ & $23.48 \pm 21.38$ & $23.46 \pm 12.97$ & 0.739 \\
\hline Hemoglobin (mg/dL) & $13.55 \pm 2.39$ & $12.45 \pm 2.25$ & $12.38 \pm 3.8$ & 0.503 \\
\hline Platelet & $224.5 \pm 88.23$ & $172.92 \pm 64.45$ & $253.67 \pm 159.57$ & 0.210 \\
\hline C-reactive Protein & $35.91 \pm 59.21$ & $92.16 \pm 129.67$ & $97.55 \pm 78.94$ & 0.208 \\
\hline Lactate & $1.36 \pm 0.81$ & $42.03 \pm 139.81$ & $1.7 \pm 1.49$ & 0.392 \\
\hline Procalcitonin & $0.22 \pm 0.43$ & $2.41 \pm 7.05$ & $0.14 \pm 0.11$ & 0.336 \\
\hline Lactate Dehydrogenase & $272.5 \pm 145.54^{\mathrm{c}}$ & $321.25 \pm 83.96$ & $802.89 \pm 817.01^{\mathrm{c}}$ & 0.014 \\
\hline Ferritin & $387.35 \pm 497.22$ & $452.4 \pm 546.24$ & $2493.29 \pm 4039.56$ & 0.047 \\
\hline Creatine phosphokinase & $132.5 \pm 179.77^{\mathrm{d}}$ & $93.67 \pm 88.06$ & $496.78 \pm 603.08^{d}$ & 0.017 \\
\hline Troponin I & $0.1 \pm 0$ & $0.17 \pm 0.24$ & $2781.29 \pm 8332.02$ & 0.241 \\
\hline D-dimer & $348.24 \pm 295.95^{\mathrm{e}}$ & $1910.17 \pm 3244.74$ & $3129.67 \pm 3979.47^{\mathrm{e}}$ & 0.070 \\
\hline
\end{tabular}


PCR test on a nasopharyngeal swab.

Detection of antibodies has been shown to improve the diagnosis of positive cases and also helpful for PCR negative patients' diagnosis. Guo et al. ${ }^{15}$ reported a significantly increased diagnosis rate with PCR and IgM ELISA assay combination (98.6\%) compared to PCR alone (51.9\%). The IgM detection rate was reported to be higher at least five days after the onset of the symptoms. We studied the Elisa test at least eight days after the onset of the symptoms. In accordance with the literature, the COVID-19 diagnosis rate was increased (14.2\% $(n=5)$ more patients) with the addition of the Elisa test.

A Chinese study about antibody response demonstrated a significant relationship between antibody titer and clinical severity 2-week after the onset of symptoms. ${ }^{15}$ Another study from China shows significantly lower virus-specific IgG levels in the asymptomatic group compared to the symptomatic group in the acute phase. ${ }^{17}$ Similar to the literature, our results show a significant relationship with Elisa test positivity and disease severity. All PCR positive patients were not developed positive $\operatorname{IgM}(n=6)$ and $\operatorname{Ig} G$ $(n=5)$ response. Since it cannot reach the statistical significance, our results show that radiologically proven, PCR and Elisa negative patients mostly have mild symptoms $(p=0.170)$. In light of the literature, we can assume that patients with mild symptoms develop lower antibody response to SARS-CoV-2. The individual time variability to develop an antibody response to the disease may have a role in a lower rate of antibody response.

An ongoing study by Sweden Public Health Agency revealed that a total of $7.3 \%$ of the blood samples collected from people in Stockholm were positive in the antibody study, which can be compared with a total of $4.2 \%$ in Skåne and 3.7\% in Västra Götaland. ${ }^{18}$ Innate immunity plays an essential role in SARS-CoV-2 clearance. ${ }^{19}$ Moreover, innate immunity alone might be enough to clear the virus. In the current study, PCR positive five mild patients were discharged without any complaints with negative IgM and IgG results 15 days after the onset of the symptoms. Furthermore, we found that positive IgG rates were significantly lower in mild patients, whereas in critical cases, it was found to be significantly high.

We found a significant relationship between D-dimer, ferritin, and LDH levels and disease severity. Zhang et al. $^{20}$ reported that elevated
D-dimer on admission correlates with hospital mortality in patients with Covid-19, which indicates D-dimer as an early and helpful prognostic marker to improve management of Covid-19 patients. In our study, we found that d-dimer levels were significantly lower in mild patients compared to critical patients $\left(\mathrm{p}=0.015\right.$,Table 5). Sun et al. ${ }^{21}$ also reported that the inflammatory markers such as ferritin, CRP level, and erythrocyte sedimentation rate were elevated in severe or critically ill groups, and D-dimer was an independent predictor of disease severity. In our study, we observe that CPK and $\mathrm{LDH}$ levels were significantly higher in critical patients' groups in addition to ferritin and d-dimer (Table 5).

Although we have presented some interesting results, our study has some limitations. First, we performed a single rapid antibody test for each patient varying 8 to 20 days after the onset of the symptoms. We did not perform a second control test that could be positive 30 days after onset of symptoms. And also, our study sample size group is small and further studies with more patients should be conducted.

\section{Conclusions}

The results of current study reveals the importance of antibody tests in severe or critical COVID-19 patients. These tests not only have an essential role in diagnosis with PCR tests but are also associated with disease severity. Severe and critical COVID-19 patients had more positive IgM and IgG antibody compared to mild patients. However, further studies should be conducted to clarify the potential association between disease severity and antibody response with more patients.

\section{Conflict of Interest}

All authors declare that they have no confict of interest.

\section{Authors' Contribution}

Study Conception: YTG, NTT, MNG; Study Design: YTG, NTT, TGK; Supervision: YTG, NTT, TGK; Funding: YTG, NTT; Materials: YTG, NTT; Data Collection and/or Processing: YTG, NTT, TGK; Statistical Analysis and/or Data Interpretation: YTG, NTT, TGK; Literature Review: YTG, NTT, TGK; Manuscript Preparation: YTG, NTT, TGK; and Critical Review: YTG, TGK. 


\section{References}

1. World Health Organization. (2020). Coronavirus disease 2019 (COVID-19): situation report, 51. World Health Organization. Available at: https://apps.who.int/iris/ handle/10665/331475. Accessed December 10, 2020.

2. Republic of Turkey Ministry, COVID-19 Information Page. General Coronavirus Table. Jul 7, 2020. Republic of Turkey Ministry of Health. Available at: https://covid19. saglik.gov.tr/EN-69532/general-coronavirus-table.html. Accessed December 10, 2020.

3. Chen N, Zhou M, Dong X, Qu J, Gong F, Han Y, Qiu Y, Wang J, Liu Y, Wei Y, Xia J, Yu T, Zhang X, Zhang L. Epidemiological and clinical characteristics of 99 cases of 2019 novel coronavirus pneumonia in Wuhan, China: A descriptive study. Lancet. 2020 Feb 15;395(10223):507-13. doi: 10.1016/S0140-6736(20)30211-7.

4. Wang D, Hu B, Hu C, Zhu F, Liu X, Zhang J, Wang B, Xiang H, Cheng Z, Xiong Y, Zhao Y, Li Y, Wang X, Peng Z. Clinical characteristics of 138 hospitalized patients with 2019 novel coronavirus-infected pneumonia in Wuhan, China. JAMA. 2020 Mar 17;323(11):1061-9. doi: 10.1001/jama.2020.1585.

5. Yang Y, Yang M, Yuan J, Wang F, Wang Z, Li J, Zhang M, Xing L, Wei J, Peng L, Wong G, Zheng H, Wu W, Shen C, Liao M, Feng K, Li J, Yang Q, Zhao J, Liu L, Liu Y. Comparative sensitivity of different respiratory specimen types for molecular diagnosis and monitoring of SARS-CoV-2 shedding. Innovation (N Y). 2020 Nov 25;1(3):100061. doi: 10.1016/j.xinn.2020.100061.

6. Zou L, Ruan F, Huang M, Liang L, Huang H, Hong Z, Yu J, Kang M, Song Y, Xia J, Guo Q, Song T, He J, Yen HL, Peiris M, Wu J. SARS-CoV-2 viral load in upper respiratory specimens of infected patients. N Engl J Med. 2020 Mar 19;382(12):1177-9. doi: 10.1056/NEJMc2001737.

7. Corman VM, Albarrak AM, Omrani AS, Albarrak MM, Farah ME, Almasri M, Muth D, Sieberg A, Meyer B, Assiri AM, Binger T, Steinhagen K, Lattwein E, Al-Tawfiq J, Müller MA, Drosten C, Memish ZA. Viral shedding and antibody response in 37 patients with Middle East Respiratory Syndrome coronavirus infection. Clin Infect Dis. 2016 Feb 15;62(4):477-83. doi: 10.1093/cid/civ951.

8. Li G, Chen X, Xu A. Profile of specific antibodies to the SARS-associated coronavirus. N Engl J Med. 2003 Jul 31;349(5):508-9. doi: 10.1056/NEJM200307313490520.

9. Hsueh PR, Huang LM, Chen PJ, Kao CL, Yang PC. Chronological evolution of IgM, IgA, IgG and neutralisation antibodies after infection with SARSassociated coronavirus. Clin Microbiol Infect. 2004 Dec;10(12):1062-6. doi: 10.1111/j.1469-0691.2004.01009.x.

10. Park WB, Perera RA, Choe PG, Lau EH, Choi SJ, Chun JY, Oh HS, Song KH, Bang JH, Kim ES, Kim HB, Park SW, Kim NJ, Man Poon LL, Peiris M, Oh MD. Kinetics of serologic responses to MERS coronavirus infection in humans, South Korea. Emerg Infect Dis. 2015 Dec;21(12):2186-9. doi: 10.3201/eid2112.151421.

11. Racine $\mathrm{R}$, Winslow GM. IgM in microbial infections: taken for granted? Immunol Lett. 2009 Aug 15;125(2):7985. doi: 10.1016/j.imlet.2009.06.003.
12. Wu Z, McGoogan JM. Characteristics of and important lessons from the coronavirus disease 2019 (COVID-19) Outbreak in China: Summary of a report of 72314 cases from the Chinese Center for Disease Control and Prevention. JAMA. 2020 Apr 7;323(13):1239-42. doi: 10.1001/jama.2020.2648.

13. CDC - Coronavirus Disease 2019 (COVID-19). Interim clinical guidance for management of patients with confirmed coronavirus disease (COVID-19). Dec 8, 2020. Centers for Disease Control and Prevention. Available at: https://www.cdc.gov/coronavirus/2019-ncov/hcp/ clinical-guidance-management-patients.html. Accessed December 10, 2020.

14. Wang W, Xu Y, Gao R, Lu R, Han K, Wu G, Tan W. Detection of SARS-CoV-2 in different types of clinical specimens. JAMA. 2020 May 12;323(18):1843-4. doi: 10.1001/jama.2020.3786.

15. Guo L, Ren L, Yang S, Xiao M, Chang D, Yang F, Dela Cruz CS, Wang Y, Wu C, Xiao Y, Zhang L, Han L, Dang S, Xu Y, Yang QW, Xu SY, Zhu HD, Xu YC, Jin Q, Sharma L, Wang L, Wang J. Profiling early humoral response to diagnose novel coronavirus disease (COVID-19). Clin Infect Dis. 2020 Jul 28;71(15):778-85. doi: 10.1093/cid/ ciaa310.

16. Zhao J, Yuan Q, Wang H, Liu W, Liao X, Su Y, Wang X, Yuan J, Li T, Li J, Qian S, Hong C, Wang F, Liu Y, Wang Z, He Q, Li Z, He B, Zhang T, Fu Y, Ge S, Liu L, Zhang J, Xia N, Zhang Z. Antibody responses to SARSCoV-2 in patients with novel coronavirus disease 2019. Clin Infect Dis. 2020 Nov 19;71(16):2027-34. doi: 10.1093/ cid/ciaa344.

17. Long QX, Tang XJ, Shi QL, Li Q, Deng HJ, Yuan J, Hu JL, Xu W, Zhang Y, Lv FJ, Su K, Zhang F, Gong J, Wu B, Liu XM, Li JJ, Qiu JF, Chen J, Huang AL. Clinical and immunological assessment of asymptomatic SARSCoV-2 infections. Nat Med. 2020 Aug;26(8):1200-4. doi: 10.1038/s41591-020-0965-6.

18. First results from ongoing study of antibodies to covid-19 virus. Sweden Public Health Agency. May 20, 2020. The Public Health Agency of Sweden 2020. Available at: https://www.folkhalsomyndigheten.se/nyheteroch-press/nyhetsarkiv/2020/maj/forsta-resultaten-franpagaende-undersokning-av-antikroppar-for-covid-19virus/. Accessed December 10, 2020.

19. Wang B, Wang L, Kong X, Geng J, Xiao D, Ma C, Jiang $\mathrm{XM}$, Wang PH. Long-term coexistence of SARS-CoV-2 with antibody response in COVID-19 patients. J Med Virol. 2020 Sep;92(9):1684-9. doi: 10.1002/jmv.25946.

20. Zhang L, Yan X, Fan Q, Liu H, Liu X, Liu Z, Zhang Z. D-dimer levels on admission to predict in-hospital mortality in patients with Covid-19. J Thromb Haemost. 2020 Jun;18(6):1324-9. doi: 10.1111/jth.14859.

21. Sun Y, Dong Y, Wang L, Xie H, Li B, Chang C, Wang FS. Characteristics and prognostic factors of disease severity in patients with COVID-19: The Beijing experience. J Autoimmun. 2020 Aug;112:102473. doi: 10.1016/j. jaut.2020.102473. 